\title{
In situ UV-Visible Assessment of Extent of Reduction During Oxidation Reactions on Oxide Catalysts
}

\author{
Morris D. Argyle \\ mdargyle@byu.edu \\ Kaidong Chen \\ Carlo Resini \\ Catherine Krebs \\ Alexis T. Bell
}

See next page for additional authors

Follow this and additional works at: https://scholarsarchive.byu.edu/facpub

Part of the Chemical Engineering Commons

\section{Original Publication Citation}

M.D. Argyle, C. Krebs, C. Resini, K.D. Chen, A.T. Bell, E. Iglesia, "Quantification of Reduced Centers in Metal Oxide Catalysts during Propane Oxidative Dehydrogenation Using UV-visible Spectroscopy." Chemical Communications, 282-283, 23.

\section{BYU ScholarsArchive Citation}

Argyle, Morris D.; Chen, Kaidong; Resini, Carlo; Krebs, Catherine; Bell, Alexis T.; and Iglesia, Enrique, "In situ UV-Visible Assessment of Extent of Reduction During Oxidation Reactions on Oxide Catalysts" (2003). Faculty Publications. 488.

https://scholarsarchive.byu.edu/facpub/488 
Authors

Morris D. Argyle, Kaidong Chen, Carlo Resini, Catherine Krebs, Alexis T. Bell, and Enrique Iglesia

This peer-reviewed article is available at BYU ScholarsArchive: https://scholarsarchive.byu.edu/facpub/488 


\title{
In situ UV-visible assessment of extent of reduction during oxidation reactions on oxide catalysts
}

\author{
Morris D. Argyle, ${ }^{a}$ Kaidong Chen, ${ }^{a b}$ Carlo Resini, ${ }^{a c}$ Catherine Krebs, ${ }^{a d}$ Alexis T. Bell ${ }^{* a}$ and Enrique \\ Iglesia*a \\ a Chemical and Material Sciences Divisions, Lawrence Berkeley National Laboratory, Department of \\ Chemical Engineering, University of California at Berkeley, Berkeley, CA, 94720-1462, USA. \\ E-mail: iglesia@cchem.berkeley.edu; bell@cchem.berkeley.edu; Fax: 510 642-4778; Tel: $510642-3789$ \\ ${ }^{b}$ (Present address) Chevron-Texaco Research and Technology Company, Richmond, CA 94802, USA \\ c (Present address) University of Genoa, Ple JF Kennedy, I-16129 Genoa, Italy \\ $d$ (Present address) Technical University of Hamburg-Harburg, 21071, Hamburg, Germany
}

Received (in West Lafayette, IN, USA) 13th May 2003, Accepted 24th June 2003

First published as an Advance Article on the web 15th July 2003

The extent of reduction of active centers during oxidative alkane dehydrogenation on $\mathrm{VO}_{x} / \mathrm{Al}_{2} \mathrm{O}_{3}$ was measured from pre-edge UV-visible spectral features and found to increase with increasing $\mathrm{VO}_{x}$ domain size and propane $/ \mathrm{O}_{2}$ ratio.

Oxidative dehydrogenation (ODH) of alkanes on $\mathrm{VO}_{x}$ and $\mathrm{MoO}_{x}$ domains involves Mars-van Krevelen redox cycles using lattice oxygen and reduced $\mathrm{V}^{3+}$ or $\mathrm{V}^{4+}$ and $\mathrm{Mo}^{4+}$ or $\mathrm{Mo}^{5+}$ as reactive intermediates. ${ }^{1,2}$ Mechanistic studies suggest that reduced centers are minority species during steady-state catalysis, ${ }^{1,2}$ a conclusion confirmed specifically for butane oxidation by in situ X-ray absorption spectroscopy. ${ }^{3}$ Our efforts to detect reduced centers during propane ODH on supported $\mathrm{VO}_{x}$ and $\mathrm{MoO}_{x}$ catalysts by near-edge X-ray absorption spectra did not succeed because of the overlapping nature of near-edge features for various oxidation states of $\mathrm{V}$ and Mo absorbers and the low concentration of reduced centers. Similar difficulties arise for near-edge absorption features in the UV-visible spectrum of oxides. Here, we report the use of pre-edge spectral features in UV-visible spectra. These $\mathrm{d}-\mathrm{d}$ transitions in reduced color centers become possible during reduction as electrons are placed within d-orbitals that are empty in oxides with cations in their highest valence state. These features appear in a spectral region devoid of strong absorption and provide more accurate measurements than previously used near-edge features in UVvisible and $\mathrm{X}$-ray spectra.

Diffuse reflectance UV-visible spectroscopy probes the electronic structure of oxide domains commonly used as alkane ODH catalysts. ${ }^{1,2,4,5}$ Edge energies depend sensitively on domain size; they reflect electron transfer in frontier orbitals that delocalize electron density during kinetically-relevant $\mathrm{C}-\mathrm{H}$ bond activation steps. ${ }^{1,2}$ Edge energies depend weakly on oxidation state, unless reduction leads to significant changes in coordination symmetry; ${ }^{4,6}$ thus, edge energies are unreliable probes of reduced centers prevalent during steady-state oxidation catalysis (e.g. vacancies and $\mathrm{OH}$ groups). Yet, previous studies reported extents of reduction obtained from near-edge spectral changes using linear interpolation between spectra for stoichiometric oxides and structurally stable suboxides by reduction in $\mathrm{H}_{2}{ }^{6-16}$

Here, pre-edge absorption features in the UV-visible spectrum of $\mathrm{VO}_{x}$ oxides are used to measure extents of reduction using calibration curves obtained from independent measurements of stoichiometric oxygen deficiencies introduced by $\mathrm{H}_{2}$ treatment at low temperatures $(603 \mathrm{~K})$. Two $\mathrm{VO}_{x} / \mathrm{Al}_{2} \mathrm{O}_{3}$ samples ${ }^{1}$ with 2.3 and $8.0 \mathrm{VO}_{x} \mathrm{~nm}^{-2}$ surface densities were used. The intensity of pre-edge features $(1.5-1.9 \mathrm{eV})$ was measured using a Cary 4 Varian spectrophotometer with a Harrick Scientific diffuse reflectance attachment (DRP-XXX), and a reaction chamber (DRA-2CR) modified to improve temperature and flow uniformity. Concurrent measurements of oxygen deficiency by on-line mass spectrometric analysis of effluent streams during $\mathrm{H}_{2}$ reduction and re-oxidation in $\mathrm{O}_{2} / \mathrm{He}$ led to the relation between absorption intensity and number of electrons transferred to $\mathrm{V}$ centers depicted in Fig. 1. These reduced centers reflect vacancies, hydroxyls, or alkoxide species present as reactive intermediates during steady-state ODH reactions ${ }^{2}$ and predominately oxygen vacancies during $\mathrm{H}_{2}$ reduction. In both cases, absorption intensities reflect the number of electrons present in metal d-orbitals. ${ }^{9}$ The inset in Fig. 1 shows that these $d-d$ transitions appear in a spectral region devoid of background absorption in fresh oxide catalysts in their highest oxidation state. Absorption at the edge arises from $\mathrm{O}$-to-V ligand-to-metal charge transitions, which are less sensitive to d-orbital occupation than $\mathrm{d}-\mathrm{d}$ transitions and appear in a much denser spectral region. The inset in Fig. 1 shows the relative magnitude of spectral changes in the pre-edge and edge region during propane $\mathrm{ODH}$ at $603 \mathrm{~K}$ on $10 \mathrm{wt} \% \mathrm{~V}_{2} \mathrm{O}_{5} /$ $\mathrm{Al}_{2} \mathrm{O}_{3}$.

The calibration curve (Fig. 1) was obtained from the amount of $\mathrm{O}_{2}$ required to restore the initial spectra after reduction in $\mathrm{H}_{2}$ at $603 \mathrm{~K}$ for time increments of $300 \mathrm{~s}$. This curve was used to measure the extent of reduction during alkane ODH from similar pre-edge intensity measurements at various reactant compositions. The calibration and in situ measurements were made in the same range of pre-edge intensities; the small extents of reduction measured during catalysis are consistent with those expected from reported ODH kinetics and mechanism in which surface oxygen appears as the most abundant reactive intermediate. ${ }^{2}$ We note that the local nature and small number of reduced centers in these oxide domains makes absorption cross-

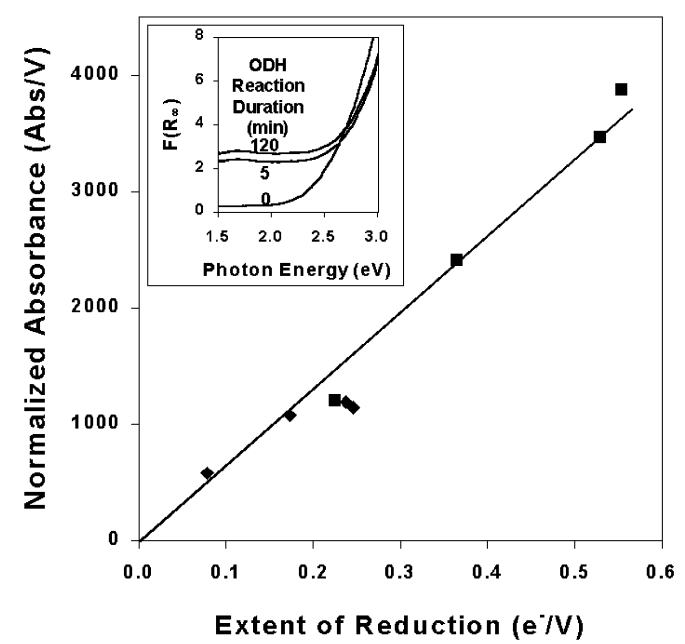

Fig. $1 \mathrm{UV}$-visible reduction response calibration curve for $\mathrm{VO}_{x} / \mathrm{Al}_{2} \mathrm{O}_{3}$ catalysts $\left[20 \mathrm{kPa} \mathrm{H}_{2}\right.$, balance $\mathrm{He}, 603 \mathrm{~K}$ reduction followed by $5 \mathrm{kPa} \mathrm{O}_{2}$, balance $\mathrm{He}, 298-773 \mathrm{~K}$ reoxidation]; $\bullet: 3.5 \mathrm{wt} \% \mathrm{~V}_{2} \mathrm{O}_{5} / \mathrm{Al}_{2} \mathrm{O}_{3}, \mathbf{\square}: 10 \mathrm{wt} \%$ $\mathrm{V}_{2} \mathrm{O}_{5} / \mathrm{Al}_{2} \mathrm{O}_{3}$. Inset: UV-visible spectra for $10 \mathrm{wt} \% \mathrm{~V}_{2} \mathrm{O}_{5} / \mathrm{Al}_{2} \mathrm{O}_{3}[603 \mathrm{~K}, 14$ $\mathrm{kPa} \mathrm{C}_{3} \mathrm{H}_{8}, 1.7 \mathrm{kPa} \mathrm{O}_{2}$, balance $\left.\mathrm{He}\right]$. 
sections proportional to the number of electrons transferred and largely insensitive to the identity of the reduced species (e.g., vacancies, $\mathrm{OH}$, alkoxides). ${ }^{2}$

Spectra were referenced to $\mathrm{MgO}$ and converted to difference spectra by dividing by $R_{\infty}$ for stoichiometric oxides (Eqn. (1)). Normalized reflectances were converted to absorbance using the Kubelka-Munk formalism (Eqn. (2)), where $K$ and $S$ are proportional to the absorption and scattering coefficients, respectively. ${ }^{17,18}$

$$
R_{\infty}=\frac{R_{\text {sample }}}{R_{\text {reference }}} \quad \text { (1) } \quad F\left(R_{\infty}\right)=\frac{\left(1-R_{\infty}\right)^{2}}{2 R_{\infty}}=\frac{S}{K}
$$

This relation between measured reflectances and sample absorbance can lead to inaccurate extents of reduction from linear interpolations between stoichiometric $\mathrm{V}^{3+}$ sub-oxides, especially for minority reduced centers, because of the strong ligand-to-metal transitions and their weak dependence on delectron densities. These factors lead to lower values of $R_{\infty}$ to larger values of $F\left(R_{\infty}\right)$, and to much poorer signal to noise ratios than obtainable in the pre-edge region.

Transient experiments showed that $60-70 \%$ of reduced centers formed during contact with $\mathrm{C}_{3} \mathrm{H}_{8}-\mathrm{O}_{2}$ were neither reversible during reaction nor catalytically relevant. These spectator reduced species appear to form via conversion of minority $\mathrm{V}_{2} \mathrm{O}_{5}$ clusters to stable suboxides, which reoxidize slowly by $\mathrm{V}_{2} \mathrm{O}_{5}$ nucleation at reaction conditions. These irreversible absorption changes include a fast initial transient upon contact with reactants $(\sim 60 \mathrm{~s})$, which is not fully reversed even after $4 \mathrm{~h}$ in $4 \mathrm{kPa} \mathrm{O}_{2}$ at $603 \mathrm{~K}$. Reversible and catalyticallyrelevant changes in pre-edge intensity were measured during exposure to $0-16 \mathrm{kPa} \mathrm{C}_{3} \mathrm{H}_{8}$ or $\mathrm{O}_{2}$ at constant $\mathrm{O}_{2}$ or $\mathrm{C}_{3} \mathrm{H}_{8}$ pressure $(4 \mathrm{kPa})$ for $300 \mathrm{~s}$. This time interval was chosen because absorption transients were accurately described as a single first-order relaxation process. Absorbances for these catalytically-relevant reduced centers were converted to extents of reduction using the data in Fig. 1 and the results are shown in Fig. 2 and Table 1. We note that total pre-edge absorption changes give much higher extents of reduction because they include irreversible reduction processes unrelated to catalytic redox turnovers, e.g., total absorption changes give 0.060 and $0.31 \mathrm{e}^{-} \mathrm{V}^{-1}$ for the 2.3 and $8.0 \mathrm{~V} \mathrm{~nm}^{-2}$ catalysts, respectively, at the conditions listed in Table 1 .

The extent of reduction during steady-state propane ODH is much lower than for stoichiometric reduction of $\mathrm{V}^{5+}$ to $\mathrm{V}^{4+}$ or $\mathrm{V}^{3+}$. These data confirm the conclusion from kinetic and isotopic studies ${ }^{2}$ that lattice oxygen atoms are the most abundant reactive intermediates during propane $\mathrm{ODH}$ on $\mathrm{VO}_{x}$ domains, even at relatively high $\mathrm{C}_{3} \mathrm{H}_{8} / \mathrm{O}_{2}$ reactant ratios. The extent of reduction was lower on the $2.3 \mathrm{~V} \mathrm{~nm}^{-2}$ sample than on the $8.0 \mathrm{~V} \mathrm{~nm}^{-2}$ sample, suggesting that the larger $\mathrm{VO}_{x}$ domains prevalent in the latter sample undergo faster redox cyles than isolated $\mathrm{VO}_{x}$ species, ${ }^{1,2}$ consistent with the observed increase in $\mathrm{ODH}$ rates (per $\mathrm{V}$ or Mo) with increasing $\mathrm{VO}_{x}$ or $\mathrm{MoO}_{x}$ domain size $^{1,19}$ (Table 1). These higher rates parallel the measured higher extents of reduction because turnover rates are limited by reduction steps involving activation of methylene $\mathrm{C}-\mathrm{H}$ bonds in propane using lattice oxygen atoms. ${ }^{2}$ The extent of reduction increases with increasing $\mathrm{C}_{3} \mathrm{H}_{8}$ or decreasing $\mathrm{O}_{2}$ pressure (Fig. 2 ), consistent with proposed ODH mechanistic steps. The data in Fig. 2 are in quantitative agreement with the expected dependence of reduced centers on $\mathrm{C}_{3} \mathrm{H}_{8}: \mathrm{O}_{2}$ (dashed curves) when oxygen vacancies are the prevalent reduced centers. ${ }^{2}$

The extents of reduction reported here for catalytically relevant species on $\mathrm{VO}_{x} / \mathrm{Al}_{2} \mathrm{O}_{3}$ are much lower than reported previously on $\mathrm{VO}_{x} / \mathrm{ZrO}_{2}$ for similar conditions and surface densities, but using total absorption edge intensity changes $(e . g$., $0.10 \mathrm{e}^{-} \mathrm{V}^{-1}$ on $\mathrm{VO}_{x} / \mathrm{Al}_{2} \mathrm{O}_{3} ; 0.60 \mathrm{e}^{-} \mathrm{V}^{-1}$ on $\mathrm{VO}_{x} / \mathrm{ZrO}_{2}{ }^{6,9} 6: 1$ $\mathrm{C}_{3} \mathrm{H}_{8} / \mathrm{O}_{2}$ ). Spectator reduced centers, perhaps in part on $\mathrm{ZrO}_{2}$ supports, ${ }^{9}$ may be responsible for these differences and also account for the higher $\mathrm{CO}_{x}$ selectivities on $\mathrm{ZrO}_{2}$-supported samples. ${ }^{1,6}$

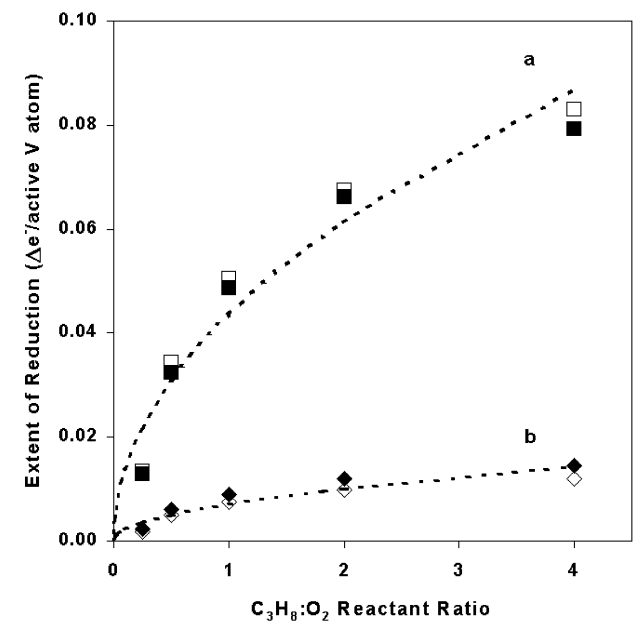

Fig. 2 Extent of reduction as a function of $\mathrm{C}_{3} \mathrm{H}_{8}: \mathrm{O}_{2}$ reactant ratio, (a) 10 wt $\%\left(8.0 \mathrm{~V} \mathrm{~nm}^{-2}\right)$, (b) $3.5 \mathrm{wt} \%\left(2.3 \mathrm{~V} \mathrm{~nm}^{-2}\right) \mathrm{V}_{2} \mathrm{O}_{5} / \mathrm{Al}_{2} \mathrm{O}_{3}[603 \mathrm{~K}$, filled symbols: $1.0-16 \mathrm{kPa} \mathrm{C}_{3} \mathrm{H}_{8}, 4.0 \mathrm{kPa} \mathrm{O}$; open symbols: $1.0-16 \mathrm{kPa} \mathrm{O}_{2}, 4.0$ $\mathrm{kPa} \mathrm{C}_{3} \mathrm{H}_{8}$; dashed lines represent $\left(\mathrm{C}_{3} \mathrm{H}_{8} / \mathrm{O}_{2}\right)^{0.5}$ dependence].

Table 1 Extent of vanadium reduction during propane $\mathrm{ODH}^{a}$

\begin{tabular}{|c|c|c|c|}
\hline $\begin{array}{l}\text { Catalyst }(\mathrm{wt} \% \\
\left.\mathrm{V}_{2} \mathrm{O}_{5} \text { on } \mathrm{Al}_{2} \mathrm{O}_{3}\right)\end{array}$ & $\begin{array}{l}\text { V surface density } \\
\left(\mathrm{V} \mathrm{nm}^{-2}\right)\end{array}$ & $\begin{array}{l}\mathrm{e}^{-} \text {transferred } \\
\text { per active } \mathrm{V}\end{array}$ & $\begin{array}{l}\mathrm{C}_{3} \mathrm{H}_{6} \text { Rate }\left[* 10^{-3}\right. \\
\mathrm{mol} \mathrm{s}^{-1} \text { (g-atom } \\
\left.\mathrm{V})^{-1}\right]\end{array}$ \\
\hline 3.5 & 2.3 & 0.020 & 0.33 \\
\hline 10 & 8.0 & 0.12 & 1.0 \\
\hline
\end{tabular}

We show here that the use of the pre-edge region in UVvisible spectra, the rigorous calibration of the intensity of these features, and the isolation of the dynamic processes relevant to catalysis from those of spectator species lead to accurate measurements of the number of reduced centers present at very low concentrations during alkane $\mathrm{ODH}$ catalysis.

\section{Notes and references}

1 K. D. Chen, A. Khodakov, J. Yang, A. T. Bell and E. Iglesia, J. Catal., 1999, 186, 325; M. D. Argyle, K. D. Chen, A. T. Bell and E. Iglesia, J. Catal., 2002, 208, 139; A. Khodakov, B. Olthof, A. T. Bell and E. Iglesia, J. Catal., 1999, 181, 205; B. Olthof, A. Khodakov, A. T. Bell and E. Iglesia, J. Phys. Chem. B, 2000, 104, 1516.

2 K. D. Chen, A. T. Bell and E. Iglesia, J. Phys. Chem. B, 2000, 104, 1292; K. D. Chen, E. Iglesia and A. T. Bell, J. Catal., 2001, 192, 197.

3 G. W. Coulston, S. R. Bare, H. Kung, K. Birkeland, G. K. Bethke, R. Harlow, N. Herron and P. L. Lee, Science, 1997, 275, 191.

4 J. G. Eon, R. Olier and J. C. Volta, J. Catal., 1994, 145, 318

5 M. A. Vuurman and I. E. Wachs, J. Phys. Chem., 1992, 96, 5008

6 X. Gao, J. M. Jehng and I. E. Wachs, J. Catal., 2002, 209, 43.

7 R. L. Puurunen, B. G. Beheydt and B. M. Weckhuysen, J. Catal., 2001, 204, 253

8 X. Gao, S. R. Bare, J. L. G. Fierro and I. E. Wachs, J. Phys. Chem. B., 1999, 103, 618

9 X. Gao, M. A. Banares and I. E. Wachs, J. Catal., 1999, 188, 325.

10 X. Gao, S. R. Bare, B. M. Weckhuysen and I. E. Wachs, J. Phys. Chem. B., 1998, 102, 10842

11 D. Wei, H. Wang, X. Feng, W. Chueh, P. Ravikovitch, M. Lyubovsky, C. Li, T. Takeguchi and G. L. Haller, J. Phys. Chem. B, 1999, 103, 2113

12 G. Grubert, J. Rathousky, G. Schulz-Ekloff, M. Wark and A. Zukal, Microporous Mesoporous Mat., 1998, 22, 225.

13 J. Melsheimer, S. S. Mahmoud, G. Mestl and R. Schlogl, Catal. Lett., 1999, 60, 103.

14 B. M. Weckhuysen, Chem. Commun., 2002, 97.

15 B. M. Weckhuysen, A. A. Verberckmoes, J. Debaere, K. Ooms, I. Langhans and R. A. Schoonheydt, J. Mol. Catal. A, 2000, 151, 115.

16 A. Brückner, Chem. Commun., 2001, 2122.

17 P. Kubelka and F. Munk, Z. Tech. Phys., 1931, 12, 593

18 G. Kortüm, Reflectance Spectroscopy, Springer-Verlag, Berlin, 1969.

19 K. D. Chen, A. T. Bell and E. Iglesia, J. Catal., 2002, 209, 35. 